\title{
Duração e élan vital no evolucionismo espiritualista de Henri Bergson
}

\author{
Duration and élan vital in the spiritualist evolu- \\ tionism of Henri Bergson
}

\author{
Rildo da Luz Ferreira \\ Pontifícia Universidade Católica do Paraná \\ Orcid 0000-0002-0459-5174 \\ rildoluz@hotmail.com
}

Resumo: Para responder nossa questão principal, isto é, saber como se estabelece, no conjunto da obra de Bergson, a relação entre a sua filosofia da duração e a hipótese evolucionista do élan vital, tentaremos reconstituir a plataforma especulativa de onde parte $A$ evolução criadora e o modo como Bergson faz da esfera da vida o ponto de intersecção entre as noções de duração e de evolução. Nosso objetivo será o de situar o contexto de emergência da noção do élan vital para aí descobrir a especificidade do pensamento de Bergson, especificidade que dá unidade à sua filosofia e marca sua contribuição para a história da filosofia. Nesse sentido, acreditamos que a teoria do élan vital não pode ser separada dessa intuição fundadora do bergsonismo que é a duração, sem ser destituída do seu significado metafísico. Assim como a consciência, o universo inteiro dura. E essa duração se caracteriza essencialmente pela liberdade. Em todo lugar onde lidamos com a vida, encontramos sob formas diversas a duração imanente à vida.

Palavras-chave: Duração; Élan Vital; Evolução; Criação; Bergsonismo. 
Abstract: To answer our main question, that is, to know how, in Bergson's work as a whole, the relationship between his philosophy of duration and the evolutionary hypothesis of élan vital is established, we will try to reconstruct the speculative platform from which Creative evolution and Bergson's way of making the sphere of life the point of intersection between the notions of duration and evolution. Our goal will be to situate the context of emergence of the vital élan image in order to discover the specificity of Bergson's thought, a specificity that gives unity to his philosophy and marks his contribution to the history of philosophy. In this sense, we believe that the vital élan theory cannot be separated from this founding intuition of bergsonism, which is duration, without being deprived of its metaphysical meaning. Like consciousness, the entire universe lasts. And that duration is essentially characterized by freedom. Everywhere we deal with life, we find in different forms the duration immanent to life. Bergsonian evolutionism translated by the image of the vital élan can then be understood as follows: the principle of life transcends life.

Keywords: Duration; Élan Vital; Evolution; Criation; Bergsonism.

\section{Introdução}

Bergson foi, sobretudo, um homem de coerência. Este seu caráter revelou-se no modo como foi dando à luz a sua produção bibliográfica, compondo nas várias obras um contínuo de sentido que a todas perpassa. Revelou-se, também, nas posições que manteve diante de determinados ideários, quer no campo político quer, especialmente, no domínio religioso ${ }^{1}$.

\footnotetext{
1 Referimo-nos, muito particularmente, à "adesão moral" de Bergson ao catolicismo - segundo as suas próprias palavras -, nunca assumida publicamente em vida devido à solidariedade do filósofo face aos ataques à religião judaica que, no ambiente antissemita e nacionalista que o escândalo do chamado "caso Dreyfus" tinha provocado na França no final do século XIX, prenunciavam já graves consequências a nível mundial. Porém, apesar deste silencio relativamente à sua conversão interior, Bergson deixa indicações testamentárias expressas para que, caso não lhe concedessem autorização para que as suas exéquias fúnebres se realizassem por um padre católico, o rabi que se encarregasse dessa função fosse informado das finais predisposições religiosas íntimas do autor. Este parece-nos constituir não só o sinal de um forte sentido moral, como sobretudo a última expressão do caráter coerente da personalidade de Bergson.
} 
E, no que diz respeito ao seu pensamento filosófico, revelou-se sobretudo no modo como, durante toda a sua carreira pública, insistiu em vincular que o essencial do seu legado especulativo residia na revelação da noção de duração. Em várias ocasiões, encontramos um autor desencantado com o modo como os conceitos vinculados pelas suas obras eram recebidos e interpretados e com a forma como era dado mais importância a aspectos que apenas faziam sentido através da ideia geral de uma filosofia da duração (BERGSON, 2002, p. 410).

Neste contexto, o contato de Bergson com os evolucionismos filosófico e científico surgiu a partir da sua concepção da vida, situando-se o fator decisivo desta abordagem precisamente no conceito de "duração". Aliás, é a partir desta noção que o autor coloca todas as grandes questões que, de obra para obra, vão orientando o seu pensamento.

O fato de A evolução criadora assumir uma vocação biológica não representou uma mudança de registro em relação às obras anteriores de Bergson, mas antes o que o próprio autor designa como uma ampliação (agrandissement) do domínio da vida interior enquanto primeiro campo de experiência (2006, p. 101). A nota final da introdução de $A$ evolução criadora e as suas primeiras páginas descrevem precisamente a passagem das conclusões do Ensaio sobre os dados imediatos da consciência e de Matéria e memória para os longos investimentos do autor nos estudos empíricos das diversas ciências dos fenômenos vitais. Esta entrada na vida íntima do Universo sedimenta-se sobre a ideia de um fluxo constante de mudança e novidade, considerada já desde 1889 como fundo da vida da consciência. A obra de 1907 buscava agora o alcance do patrimônio especulativo acumulado até então. Nesse sentido, acreditamos que será um passo importante e necessário para nossa pesquisa começarmos este capítulo tentando reconstituir a plataforma especulativa de onde parte $A$ evolução criadora e o modo como Bergson faz da esfera da vida o ponto de intersecção entre as noções de duração e de evolução. 


\section{A duração como realidade psico-bio-cósmica}

Se olharmos o primeiro capítulo de A evolução criadora, nos deparamos, logo de cara, com dois aspectos susceptíveis de serem resumidos em duas frases simples que nos dão uma ideia do itinerário percorrido até à concepção do élan vital, como ponto culminante da duração: a vida psicológica muda, isto é, dura; o universo, enquanto conjunto de quaisquer objetos materiais, muda, quer dizer, dura.

Com a afirmação de que a vida psicológica dura Bergson recapitula o Ensaio. Começa chamando a atenção para o fato de a minha existência ser o que eu melhor conheço, para reproduzir depois afirmações com as quais previamente nos familiarizou. Pelo seu tom categórico, vale a pena retirar de A evolução criadora alguns exemplos. Escreve o filósofo: "Verifico em primeiro lugar que passo de um estado para outro (...). Assim, mudo constantemente. Mas isso não é tudo. A modificação é muito mais radical do que pode parecer à primeira vista" (2005, p. 15). Acautela, em seguida, a objeção que pode derivar do fato de eu falar dos meus estados, como se formassem um bloco, de onde se poderia afirmar que neles não há mudança. Todavia, um leve esforço de atenção revela que todos eles se modificam, momento a momento. Essa mudança contínua, transformando continuamente os estados psíquicos, provoca esta bela imagem: "O meu estado de alma, progredindo na estrada do tempo, cresce continuamente com a duração que acumula e faz, por assim dizer, uma bola de neve consigo mesmo" (2005, p. 16).

Bergson insiste na apreciação da vida psicológica nos seus diversos estados. Isso pode conduzir ao sentimento de certa descontinuidade, logo considerada como mera aparência. Na verdade, o que existe é a totalidade como estrutura globalizante ou como globalidade estruturante num fundo contínuo. $\mathrm{O}$ fato de poderem dar-se aparições descontínuas, por motivos relacionados com a vida prática, em nada enfraquece o pensamento do filósofo, que escreve: "Se um estado de alma deixasse de variar, a sua duração deixaria de existir" (2005, p. 16). Bergson utiliza a palavra francesa couler, literalmente correr, mas que, na realidade, quer dizer existir. No contexto apresentado, significa que a variação ou mudança se identifica com a dura- 
ção, de tal modo que, onde não houver mudança, não pode haver duração. Esta, deixando de correr, deixará de existir. Isto quer dizer que a duração de qualquer estado de alma está no seu incessante variar, no seu mudar contínuo, no seu contínuo fluir. A sua essência está na mudança, de tal modo que, se esta faltar, falta a própria essência da duração.

Bergson fala do eu como substrato da mudança dos estados psicológicos, para logo se pronunciar pela não realidade desse substrato. É que, se a nossa existência se compusesse de estados separados, de que um eu impassível tivesse que fazer a síntese, não haveria duração para nós. "Porque um eu que não muda não dura" (2005, p. 18). E o mesmo se pode dizer de cada um dos estados psicológicos: se não mudam, não duram. Por isso, dada a mudança própria de cada estado de alma, compreende-se que cada momento da nossa personalidade seja novo e imprevisível. Cada estado "é um momento original de uma não menos original história" (2005, p. 21). Bergson termina esta recapitulação do Ensaio, dizendo que não podemos agir neste domínio, como na geometria, onde tudo é dado de uma só vez, impessoalmente, impondo uma conclusão igualmente impessoal. Aqui, não se pode operar in abstracto, de fora, como em geometria, nem resolver por outrem os problemas que a vida põe a cada um. Os problemas são concretos, vividos pessoalmente. Por isso, a pessoa que os tem é quem os deve resolver, assumindo-os como seus e colocando-se no seu interior: "A cada um compete resolvê-los por dentro, por sua conta” (2005, p. 22).

Até aqui, o resumo do Ensaio feito em $A$ evolução criadora. Para prosseguir, Bergson desencadeia um novo passo, com a seguinte questão: Qual o significado preciso da palavra "existir" para a nossa consciência? E a resposta surge imediatamente: "Para um ser consciente, existir consiste em mudar; mudar em amadurecer; amadurecer em se criar indefinidamente. Poderá dizer-se o mesmo da existência em geral?" (2005, p. 22). Em outras palavras: O que dizemos da nossa vida psicológica poderá aplicar-se à existência em geral ${ }^{2}$ A resposta a esta interrogação nos colocará às portas do élan vital.

$2 \quad$ No fundo, estava em causa a pergunta por aquilo que se passava fora da consciência, para lá da vida interior do sujeito e, em última instância, para lá da vida individual de cada ser organizado. 
É o que veremos, avançando na nossa análise, como que conduzidos pela mão de Bergson. O universo, enquanto conjunto de quaisquer objetos materiais muda/dura. Se Bergson mostrar $^{3}$ a verdade desta afirmação, é um dado adquirido que a duração goza de aplicabilidade universal, já que não é somente do ser consciente que ela se pode afirmar, mas de qualquer objeto tomado ao acaso, desde que integrado no todo. É o que Bergson se esforça por mostrar. Com efeito, atendo-nos aos objetos materiais do universo, parece que neles tudo nos fala de imutabilidade. Tudo parece indicar que não há neles mudança. Numa curiosa expressão bergsoniana, a aparente fixidez dos objetos gera em nós a crença de que o "o tempo não os atinge" (2005, p. 23). No entanto, a sucessão é um fato incontestável, mesmo no mundo material. Por mais que os nossos raciocínios sobre os sistemas isolados impliquem que a história passada, presente e futura deles poderia desdobrar-se de uma só vez, à maneira de um leque, o que é certo é que ela não se desenrola menos progressivamente, como se ocupasse uma duração análoga à nossa. Há, portanto, uma sucessão, um tempo de espera, coincidente com a minha impaciência, isto é, com algo da minha duração que eu não posso ampliar nem reduzir a meu bel-prazer. É o que mostra um fato insignificante, mas que encerra profundas ligações: o exemplo de um copo d'água açucarada ${ }^{4}$. Se em casos como o do açúcar a derreter-se na água, sistemas parciais que a ciência isola e explora artificialmente, assistimos ao escoamento da duração - porque somos obrigados a esperar que o açúcar desça para o fundo do copo para que se produza a água doce -, é só porque, em última instância, estão integrados no conjunto da realidade. Assim, nunca é possível isolar absolutamente uma parcela do mundo material. Não se podendo quebrar a relação de cada coisa ao todo cósmico, e sendo o

3 Veremos que, numa filosofia da intuição, como a de Bergson, o filósofo não demonstra, apenas mostra. Por isso, não recorre a demonstrações apoiadas em argumentos bem constituídos; descreve, principalmente, o que aparece, de modo que, afastando os impedimentos da visão, leve os outros a ver.

$4 \quad$ Segundo Arnaud François, especialista responsável pelo volume $A$ evolução criadora da edição crítica das obras de Bergson, este exemplo surge pela primeira vez num curso de Bergson no Collège de France, no ano letivo 1901-1902 (BERGSON, 2007, p. 397-398). 
Universo em geral que dura, é por essa ligação que as coisas tomadas isoladamente também duram. Até porque estes objetos materiais que nós insistimos em recortar do fundo da realidade não existem enquanto tal, sendo a sua delimitação espacial apenas um subterfúgio que a ação reclama da inteligência e que é corroborado pelas ciências de pendor matemático.

Se deixarmos agora a análise de casos banais e considerarmos casos mais complexos (por exemplo, o caso de sistemas isoláveis, nomeadamente o sistema solar), daremos conta de que, mesmo aí, os sistemas interagem, sujeitos como estão a influências recíprocas, provocando um conjunto de mudanças daí decorrentes. Portanto, mesmo nesses casos, o isolamento não é completo, verificação que leva Bergson a fazer esta afirmação categórica: "O universo dura" (2005, p. 25), entendido como conjunto dos objetos em geral. Esta certeza da duração imanente ao Todo do universo e de qualquer objeto ou sistema enquanto integrado no Todo, é muito importante, pelas consequências que leva consigo. Se o universo como Todo dura, a duração se reveste de aplicabilidade universal, psico-cósmica. Por outro lado, o universo não está totalmente feito, mas, mergulhado na duração, participa das suas propriedades de invenção, criação de formas, elaboração contínua do absolutamente novo. Com estas expressões, estamos mesmo às portas da duração como élan vital, já que se torna necessário, a partir de agora, descobrir a raiz dessa energia criativa.

Na tentativa de mais um passo, surgem novas questões: no conjunto dos objetos materiais, não haverá alguns objetos privilegiados? Serão os corpos vivos como os outros? A evolução criadora analisa cuidadosamente este domínio dos seres vivos, discutindo as suas propriedades características de individualidade, de organização, de criação contínua, distinguindo-os de todos os outros. Eles não podem comparar-se a um objeto. Quando muito, poderíamos encontrar um termo de comparação na totalidade do universo material. Como anteriormente, resumiríamos esta ideia em uma frase simples, que seria o terceiro aspecto a ser destacado das primeiras páginas d'A evolução criadora: o universo privilegiado, abarcando alguns objetos materiais, os seres vivos, dura. Bergson faz ques- 
tão de sublinhar esta ideia, porque sabe que aí reside a raiz dessa energia criativa própria da duração. A partir de agora, os seres vivos passam a primeiro plano. Nas palavras de Leonardo Coimbra, "é a odisseia da vida que Bergson nos apresenta em $A$ evolução, as suas aventuras, ou antes, a sua profunda intenção aventureira e inventiva" (1994, p. 192). E, um pouco mais a frente, em expressão típica, Coimbra refere o pensamento de que a vida dura e ninguém pode biologicamente refazer as suas manhãs (1994, p. 196). A duração amplia, assim, o seu âmbito de aplicação. Ela passa a ser uma realidade psico-bio-cósmica. Trata-se de uma visão duracional do universo. Podemos assim enumerar as coisas que duram: o ser consciente, os seres vivos e o universo no seu conjunto. A isso nos autorizam as palavras de Bergson: "Tal como o universo no seu conjunto, tal como cada ser consciente de per si, o organismo que vive é algo que dura. O seu passado prolonga-se inteiro no seu presente e aí permanece atual e agindo" (2005, p. 30).

\section{Hipótese evolucionista: o élan vital}

Bergson não pretende parar aqui. Quer avançar mais. Continua, por isso, a se interrogar, provocando um aprofundamento no sentido de ligar a vida à consciência: "Poder-se-á ir mais longe e dizer que a vida é invenção, tal como a atividade consciente, e como ela criação incessante?" (2005, p. 38). A solução do problema da vida vai ser situada no quadro da hipótese evolucionista, à luz de uma concepção correta da duração. Esta é a única refutação possível das outras teorias da vida ${ }^{5}$, desde o mecanismo ao finalismo, desde o darwinismo ao neolamarckismo, insuficientes para darem uma explicação satisfatória, porque marcadas pelo mesmo vício. Nelas, tudo está dado. Partindo do já feito, com desprezo pelo fazer-se e, por conseguinte,

$5 \quad$ É necessário termos sempre presente que, se $A$ evolução criadora discute a biologia transformista da época, é porque, em primeira instância, se orienta pela questão mais vasta da verdadeira essência da vida. Neste aspecto, fazemos eco da posição de Alexis Philonenko, para quem o caráter íntimo da filosofia bergsoniana é metafísico, significando que é enquanto filósofo e não enquanto biólogo especializado que Bergson (per) segue o problema da evolução (PHILONENKO,1994, p. 253). 
pelo tempo, se recusam a ver na vida uma criação imprevisível. Assentam na base de que o mesmo se obtém pelo mesmo. Partem do princípio de que as mesmas causas produzem sempre os mesmos efeitos. São doutrinas deterministas. Esta refutação a partir da noção de duração adquire tanto mais rigor e tanto mais força probatória, quanto mais francamente nos colocamos na hipótese evolucionista. Só a evolução nos pode dar garantia de apanharmos a duração como a nossa consciência a apanha, isto é, como nos é dada na nossa experiência. Na verdade, nós percebemos a duração como uma corrente que não se pode voltar a subir. É o fundo do nosso ser e a própria substância das coisas com as quais estamos em comunicação.

Para evidenciar mais a importância da evolução enquanto quadro metodológico de solução do problema da vida, recolhemos de $A$ evolução criadora a seguinte frase, apreciável pela contundência das expressões utilizadas: "A duração real é aquela que morde as coisas e nela deixa a marca dos dentes. Se tudo está no tempo, tudo muda interiormente, e a mesma realidade concreta nunca se repete" (2005, p. 61). A imagem dos dentes que mordem e trincam, repetidamente usada por Bergson, adquire um significado especial revelador da característica profunda da duração. Durar, ser duração, viver em duração, equivale a não ser o mesmo em dois momentos sucessivos. Os dentes, mordendo, modificam o objeto mordido. Assim, a duração, mordendo continuamente a realidade, modifica-a ininterruptamente, tornando-a sempre nova, nunca repetida.

Coimbra compreendeu bem este pensamento, ao afirmar: "Uma das ideias fundamentais do bergsonismo é a ideia da imprevisibilidade da vida" (1994, p. 9). É a filosofia evolutiva da vida bergsoniana que pretende ultrapassar, ao mesmo tempo, o mecanismo e o finalismo, embora, na própria expressão bergsoniana, se aproxime mais deste que daquele (BERGSON, 2005, p. 66). Continuando a referir-se à vida e em sintonia com esta perspectiva, Coimbra escreve: "Nem mecanismo, nem finalismo, mas um élan, um jorramento de vitalização energética, deixando fim e causas pelo caminho do seu heroico percurso" (1994, p. 207). Mas só colocando-nos a hipótese do evolucionismo, poderemos mostrar pelos fatos a insuficiência 
dessas teorias. Neste contexto, Bergson apresenta a hipótese da evolução como ponto de partida da sua teoria, não um evolucionismo falso, à maneira de Spencer em que a realidade atual, evoluída, é parcelada em elementos, também eles evoluídos, e depois, refeita com esses elementos, dando-nos assim como antecipadamente explicado o que se pretendia explicar, mas um evolucionismo verdadeiro em que a realidade é seguida na sua geração e no seu crescimento.

O modo como Bergson conduz a sua investigação acerca dos problemas da vida parece indicar que o termo élan não lhe apareceu repentinamente e com facilidade, mas lhe surgiu como o mais adequado, ao fim de um processo longo e moroso. Na realidade, percorrem-se páginas e páginas de $A$ evolução criadora, desde temas já descritos até à discussão das teorias explicativas da vida, sem encontrar esse vocábulo, e é precisamente no quadro dessa discussão e no contexto da refutação dessas teorias, que a palavra élan é utilizada pela primeira vez.

Mecanismo e finalismo desprezam o tempo. Ora, numa perspectiva de duração, o tempo é imprescindível. Está em tudo e tudo está no tempo, provocando contínua mudança. Deste modo, a realidade concreta, no seu contínuo fluir, é irrepetível. A repetição é obra da inteligência. Portanto, só é possível em abstrato. É a inteligência que, destacando alguns aspectos da realidade e os imobilizando por exigências da vida prática, possibilita a sua repetição. Preocupada como está com os aspectos repetíveis que isolou e imobilizou, não tem disponibilidade para atentar ao tempo. Trata-se simplesmente da lei psicológica da atenção-distração aplicada à inteligência na sua relação com a repetição e com o tempo. A incidência da atenção num aspecto implica a distração dos outros aspectos e, quanto mais a atenção se concentra num aspecto, mais se desvia dos outros. O mesmo se passa com a inteligência. Concentrada como está na necessidade de repetição, por exigência da ação, deixa de atentar ao tempo. "Repugna-lhe o fluente e solidifica tudo aquilo que toca" (BERGSON, 2005, p. 61). Bergson exprime, nas suas obras, várias vezes e sob diversas formas, um pensamento que lhe é muito caro e que poderíamos traduzir nas 
seguintes palavras: o tempo real não se pensa, vive-se, porque a vida ultrapassa a inteligência.

No movimento interior, característico da vida, a inteligência destaca um ou outro aspecto que expressa em conceitos e o constitui em núcleo intelectual ou conceitual. Mas esses aspectos não são toda a realidade. Esta é constituída, se quisermos falar assim, por esse centro ou núcleo conceitual e por tudo o que se desenrola à sua volta, como zona indefinida, por aquilo que Bergson designa de "franja indecisa que vai perder-se na noite" (2005, p. 62), já anunciada na introdução como nebulosidade vaga, feita da própria substância, à custa da qual se formou o núcleo luminoso que chamamos inteligência. $\mathrm{O}$ núcleo contém todos os aspectos abstraídos pela inteligência e expressos em conceitos, constituindo um depósito obtido por via de condensação. A franja indecisa é uma zona indefinida, indeterminada, que Bergson denomina de fluida, por oposição a condensada e que caracteriza com adjetivos, como indistinta, vaporosa. A massa fluida da franja indecisa, condensando-se, dá origem ao núcleo, verdadeiro depósito de conceitos solidificados. Por isso, núcleo e franja não diferem radicalmente, sendo ambos necessários para recuperar toda a realidade do movimento interior da vida.

Vê-se agora melhor a posição do mecanismo e do finalismo, diante dessa problemática: ligam apenas ao núcleo que brilha no centro, com total desconhecimento da franja indecisa. A nosso ver, tem muita importância este aspecto do pensamento de Bergson. Com efeito, para o filósofo, essa franja fluida, indecisa, indistinta, indeterminada, parece ser mais importante que o próprio núcleo. Por um lado, mostra, por contraste, que o núcleo encerra em si uma potência mais ampla que se obteve por condensação: ele faz supor a franja que o cerca. A franja indistinta evoca, naturalmente, a sua origem comum com a do núcleo conceitual.

Outro aspecto interessante do pensamento de Bergson, que vai desembocar diretamente no uso da palavra élan, é a inclinação da nossa razão para catalogar o real e encerrá-lo nos seus quadros pré-existentes. Diante de um objeto novo, a ra- 
zão pergunta imediatamente em qual dos seus compartimentos (Bergson utiliza o termo tiroir) irá entrar e qual dos vestidos já feitos lhe servirá. Platão, com as suas ideias, e Aristóteles, com as suas categorias, são disso claro exemplo. No entanto, a história da filosofia mostra o conflito de sistemas, a impossibilidade de adaptar o real aos vestidos de confecção em série (entenda-se: aos nossos conceitos completamente feitos, autênticos modelos estandardizados), a necessidade de trabalhar o real concreto e os seus diversos aspectos, cada um com a sua medida adequada. Este método da catalogação do real e do seu encerramento em quadros pré-fabricados é inaceitável, particularmente no que respeita às teorias do mecanismo e do finalismo. Se a vida se processa evolutivamente em linhas divergentes, abandonando pelo caminho elementos incompatíveis com o seu particular modo de organização em favor de outras linhas de desenvolvimento, é a totalidade desses elementos que importa aprofundar. Seremos ajudados pela tal franja de representação confusa que circunda o centro luminoso da nossa representação distinta, isto é, a representação intelectual: "É daí que poderemos tirar o élan necessário para nos elevarmos acima de nós próprios" (BERGOSN, 2005, p. 65). Nesta passagem, escreve-se, pela primeira vez, a palavra élan. Parece tratar-se de um longo itinerário, à procura do melhor termo, para significar, nesta altura da especulação de Bergson, o seu pensamento. E eis que surge a palavra própria: Élan! Poderíamos traduzi-la por impulso, mas o uso filosófico já a consagrou na nossa língua, nos sentindo, por isso, autorizados a utilizá-la no próprio original, até porque qualquer termo que usemos para traduzi-la em português empobreceria o seu sentido primitivo. Ela aparece no quadro da refutação das teorias da vida que Bergson considera insuficientes.

Bergson usou a expressão élan vital ao tratar das possibilidades ou potencialidades do élan. O essencial de toda a vida, animal e vegetal, está num esforço para acumular energia e, a seguir, despendê-la em canais flexíveis, deformáveis, em cuja extremidade realizará trabalhos infinitamente variados. Seria essa a tarefa do élan vital que, "atravessando a matéria, quereria obter de uma só vez" (2005, p. 277), se a sua potência 
fosse ilimitada ou se algum auxílio lhe pudesse vir de fora. Mas o élan é finito, não podendo superar todos os obstáculos. Por isso, sua história é feita de luta contínua: desde o élan vital, impulso inicial finito, até aos mais altos graus de evolução, a luta continua. Como se vê, a expressão élan vital aparece para dizer que se trata de uma força inicial finita que encontra pela frente vários obstáculos com os quais tem que lutar continuamente na caminhada evolutiva que se lhe depara como essencial. E, nessa luta, ora vence, ora é vencido, sendo o seu movimento ora desviado, ora dividido, mas sempre contrariado, "e a evolução do mundo organizado não é senão o desenvolvimento dessa luta" (BERGOSN, 2005, p. 278).

Bergson parte do transformismo que, embora não esteja cientificamente provado, é, para ele, a única hipótese possível de explicação da vida. É disso que trata em todo o capítulo primeiro de $A$ evolução criadora, significativamente intitulado: "Sobre a evolução da vida. Mecanismo e finalidade" (2005, p. 15). Aí se esforça Bergson por mostrar a insuficiência das grandes teorias explicativas da vida, mecanismo e finalismo, em voga no século XIX, concluindo que todas as investigações científicas apontam para a teoria da evolução. Esta não pode encontrar suficiente explicação no recurso a forças físico-químicas, em que as partes se unem como peças de uma máquina. Ao contrário, a evolução deve explicar-se, como se houvesse uma corrente dinâmica subjacente a todas as transformações, um élan vital entendido como uma espécie de alma de toda a realidade. Esse élan vital é o manancial interior e primitivo de onde brotam todas as coisas, dando origem a um processo evolutivo que age como um todo. Conhecido por intuição, nele se revela a conservação do passado como sendo a substância do presente. O passado, que se conserva no presente com toda a sua força, exige a criação de formas novas, não atraído pelo futuro ou por qualquer fim pré-existente que o seduza pela frente, mas impelido por uma força originária colocada atrás. Bergson chama-lhe vis a tergo, ao escrever:

Se a vida realiza um plano, deverá manifestar uma harmonia mais elevada à medida que avançar mais. Assim, a casa desenha cada vez melhor a ideia do arquiteto à medida que as pedras se erguem 
umas sobre as pedras. Pelo contrário, se a unidade da vida se acha por inteiro no élan que a impele ao longo da estrada do tempo, a harmonia não se acha em frente, mas atrás. A unidade vem de um vis a tergo: é dada no início como impulso e não afirmada no fim como atrativo (2005, p. 120-121).

O élan vital é, pois, uma força criadora, uma evolução incessantemente renovada. O sinal natural desta evolução é para frente, não no sentido de ação predeterminada ou de representação prévia de um fim a atingir, mas no sentido de que a sua efetivação se dá por virtude do ímpeto original. A harmonia, porém, que deriva da unidade desse impulso verifica-se atrás, na fonte de onde provém. É um gérmen de vida, cuja ação evolutiva não está terminada. O seu poder criativo continua a exercer-se em todo o universo. É de influência retroativa.

Nada melhor para concluir este aspecto do élan vital do que ouvir, mais uma vez, o próprio Bergson que, ao referir-se à hipótese de um élan original, excluída pelo mecanismo, o define assim: "Um ímpeto interior que impulsionaria a vida, por meio de formas cada vez mais complexas, para destinos cada vez mais elevados" (2005, p. 119).

\section{O élan vital ou a criação como ato}

Qual o significado desta abrangência cósmica do élan vital? O que acaba de ser dito parece significar que, em tudo, permanece a força original, sempre significativa da presença do élan vital. E isso nos dá uma certeza: a de que a duração é um movimento que se identifica com toda a realidade, penetrando-a intimamente, mas tem a sua fonte no élan vital, que, por explosão inicial, provocou uma fragmentação de elementos, alguns dos quais sobreviveram, ramificando-se em três direções principais.

A evolução é um movimento que sobe até ao homem, mas tem a sua origem no élan vital, estabelecido sobre os dados da biologia. Uma vez em marcha, esse élan acompanha e penetra o homem, sempre atuante e formando com ele uma unidade pluridirecional: um presente abarcando o passado que nele se prolonga e condensa, e o futuro no qual se projeta, o perseguindo contínua e inseparavelmente, formando com ele 
uma unidade, tal como a sombra que, projetada para frente, é seguida por quem a faz, sem nunca a alcançar.

Assim, a imagem do élan vital, construída a partir de uma dupla perspectiva metodológica, permite abordar o problema que encerra a vida. Essa imagem é, ao mesmo tempo, o resultado de uma confrontação com as ciências biológicas e o conteúdo sugerido por uma intuição profunda do fenômeno da vida. Como dissemos anteriormente, as tentativas de redução físico-químico da vida revelam insuficiências quanto ao conhecimento que podem produzir ${ }^{6}$ : o reducionismo mecanicista promovido pelas ciências naturais e algumas correntes do pensamento filosófico, cujo evolucionismo spenceriano constitui o paradigma, não podem explicar a vida. A imagem do élan vital nasce da constatação dos limites do procedimento mecanicista nas ciências e de uma visão imediata, intuitiva da experiência. Ela "segue a experiência" de modo integral, enquanto surgi de um trabalho fecundo de confrontação e apresenta assim um “caráter claramente empírico" (BERGSON, 1978, p. 93).

O élan vital, se ele sugere o que sabemos do processo vital sem esgotar-lhe o conhecimento completo ${ }^{7}$, permanece uma imagem em Bergson. Ele é imagem, não no sentido onde o conhecimento da vida só seria possível no interior de uma imagem poética ${ }^{8}$, que lhe desqualificaria as pretensões à certe$\mathrm{za}^{9}$. Ele é imagem no sentido de que não podemos identificá-lo precipitadamente com um princípio explicativo contendo em

\footnotetext{
$6 \quad$ É o que revela o exemplo de um fenômeno de "heteroblastia", no capítulo I de $A$ evolução criadora. Esse termo, cujo sentido é explicado por Bergson, foi criado pelo biólogo Salensky "para designar os casos em que se formam nos mesmos pontos, em animais parentes entre si, órgãos equivalentes cuja origem embriológica é, contudo, diferente” (BERGSON, 2005, p. 92). $7 \quad$ Com o élan vital, "tem-se uma ideia carregada de matéria, empiricamente obtida, capaz de orientar a pesquisa, que resumirá por alto o que sabemos do processo vital e que assinalará também o que dele ignoramos" (BERGSON, 1978, p. 96).

8 É conhecida a crítica de Bertrand Russell contra o projeto bergsoniano de A evolução criadora: simples filosofia mística, fazendo do "instinto o único árbitro da verdade metafísica” (RUSSELL, 2002, p. 52, tradução nossa). 9 "Queremos a certeza, - a certeza para a filosofia como para a ciência” (BERGSON, 1972, p. 886).
} 
si, já dado, todas as determinações do real e da vida ${ }^{10}$, embora permaneça que, no capítulo III de A evolução criadora, o élan vital ganhe uma dimensão cósmica, e contribua para forjar uma cosmologia aberta pela filosofia das tensões de duração do quarto capítulo de Matéria e memória.

Pensar a vida a partir da imagem do élan vital é o ponto de partida de uma compreensão da vida como vida criadora, e consequentemente, das dificuldades que ela encontra no seu desenvolvimento criador. Contra uma abordagem totalizante e exclusiva da evolução da vida a partir da hipótese darwiniana das variações acidentais, aquela da seleção natural ou ainda a partir daquela, lamarckiana, da hereditariedade dos caracteres adquiridos, a criação filosófica dessa imagem recusa na verdade uma compreensão do processo evolutivo como simples redistribuição de matéria e de movimento. Nem o mecanismo, nem o finalismo, esse "defensor insincero da vida", para parafrasear Jankélévitch (1975), dizem alguma coisa sobre a totalidade do fenômeno vital e do problema que ele deve resolver.

O processo evolutivo da vida é compreendido como a divisão de um ato simples, e não como a combinação de meios em vista de um fim predeterminado. Esse ato simples, pura atividade criadora, contorna as resistências, os obstáculos que uma matéria lhe opõe, que tende a dividir seu movimento fragmentado-o. Essa fragmentação faz surgir várias tendências, das quais a inteligência e o instinto formam as duas grandes linhas específicas, animal e humana. A imagem do élan vital, na medida em que ele sugere a unidade de uma impulsão se dividindo numa multiplicidade de efeitos ao contato com a matéria, descreve a efetividade de um esforço, que não se faz de uma vez, e que implica uma duração. O surgimento de novas espécies e as suas

10 Com relação à escolha da imagem do élan vital, acreditamos oportuno o comentário de Bento Prado Júnior: "A noção de impulso vital aparece caracterizada, como já observamos, apenas como uma imagem, que reflete de maneira aproximada a originalidade da vida. Mais do que qualquer outra imagem, ela veicula as várias significações de que é carregada a vida. [...] A imagem aproximada reenvia-nos a um pensar finito que sempre se corrige na empresa de sistematização da experiência, e não como um saber absoluto ou uma visão de Deus. É, com efeito, impossível deixar de notar o caráter empírico e, por assim dizer, provisório, dessa noção" (1989, p. 212, grifo do autor). 
variações internas, assim como os corpos vivos individuados que pertencem as essas espécies, são as soluções reais que propõe a vida diante das condições de propagação que lhe são feitas. Uno, como ato simples, e múltiplo, como potência virtual de diferenciação, o élan vital caracteriza a exigência da vida enquanto ela se manifesta naquilo que ela realiza, os seres vivos.

Essa imagem do élan vital é especificada a partir do triplo emprego que se faz dela: positivo, prático e crítico. Ela é comprovação dos fatos positivos de criação; ela sugere uma descrição dos processos operantes internos à vida; ela propõe a recusa de dois modelos da criação, teológico e antropológico.

Positivamente, a vida é uma continuidade de progresso, força de crescimento na medida em que ela tira de si mesma mais do que tem. Todavia, ela é limitada pela resistência que a matéria lhe opõe, e cujo movimento é atestado nos seres vivos:

"A vida não pode progredir senão por intermédio dos vivos, que são
os seus depositários. É necessário que milhares e milhares deles,
mais ou menos semelhantes, se repitam uns aos outros no espaço e
no tempo para que cresça e amadureça a novidade que eles elabo-
ram" (BERGSON, 2005, p. 254)

De um ponto de vista crítico, não há criação ex nihilo ${ }^{11}$. $\mathrm{O}$ que surge no mundo não surge do nada, mas tem uma origem, que é élan de vida, e participa do crescimento do todo da realidade de forma contínua, indivisa. Por outro lado, a atividade criadora da vida não é concebida sob um modelo produtivo, supondo um sujeito/agente produtor e uma coisa/objeto produzido. Na vida, não há um sujeito que cria e coisas que são criadas $^{12}$. A atividade criadora da vida é um processo de crescimento interno, imanente ao seu próprio movimento: ele é processo de criação sem sujeito.

De um ponto de vista prático, essa concepção desteologizada e desantropologizada da criação, trazida pela imagem

11 Na Bíblia cristã, a maior parte dos relatos da criação não são ex nihilistas. Uma expressão clara da criação ex nihilo aparece num texto tardio, redigido em grego, que é aquele do capítulo 7 do $2^{\circ}$ livro dos Macabeus.

12 "Tudo é obscuro na ideia de criação se pensarmos em coisas que seriam criadas, e em uma coisa que se cria [...]" (BERGSON, 2005, p. 271). 
do élan vital, instrui o conhecimento da vida em Bergson, no centro do qual está inscrito a tematização do "nível antropológico"13. As operações de criação podem ser compreendidas no interior de um duplo regime induzido pela própria natureza do élan vital que é, ao mesmo tempo, origem dinâmica da vida, como unidade de impulsão, e esforço ${ }^{14}$, encontrando diante de si o obstáculo da matéria que limita seu poder criador. A criação se apresenta, por um lado, como um ato: o élan vital é "exigência de criação" (BERGSON, 2005, p. 275). Por outro lado, a criação indica um resultado, o criado, que remete a um processo de individuação que resulta de uma operação de divisão pela matéria dando origem a uma pluralidade de espécies e individualidades vivas. A materialidade, na medida em que ela se opõe ao élan, "[exprime] tão somente a distinção entre o que é criado e o que cria" (BERGSON, 1978, p. 211). O conceito de criação é um conceito relacional que descreve o processo genético da vida em sua imanência.

A caracterização do élan vital como "exigência de criação" pode ser compreendida da seguinte maneira em $A$ evolução criadora:

Se, no seu contato com a matéria, a vida pode ser comparada a um impulso ou a um élan, considerada em si mesma é uma imensidão de virtualidade, um apinhar-se de mil e uma tendências que todavia só serão "mil e uma" depois de exteriorizadas em relação umas às

13 Não se trata, para Bergson, de fazer da questão do homem um centro, reconduzindo uma promoção teórica e ética da humanidade. Ela constitui, antes, o momento necessário de uma travessia - e mesmo de uma travessia cósmica - partilhando os caminhos que a vida toma para resistir àquilo que impede seu progresso criador. De acordo com Lapoujade, "o nível antropológico está contido entre realidades contínuas mais vastas que ele, inferiores ou superiores a ele, que se encolhem e se condensam quando entram na forma humana propriamente dita" (2010, p. 63-64). A questão do homem, longe de ser aquela de sua essência é, antes de tudo, a do seu significado para a vida criadora. Visto que ela nasce de uma compreensão originária e primitiva da vida, é preciso circunscrever, na própria imanência do fato vital, o problema que encontra a vida no seu jorramento e compreender como, de maneira descentralizada, mas necessária, a humanidade aparece como o esboço de uma solução para esse problema.

"Efetivamente, todas as nossas análises nos mostram na vida um esforço para escalar a vertente que a matéria desce" (BERGSON, 2005, p. 269). 
outras, isto é, uma vez espacializadas. O contato com a matéria decide sobre essa dissociação. Efetivamente, a matéria divide o que só virtualmente era múltiplo. (BERGSON, 2005, p. 282).

Dois modos de ser da vida, na medida em que ela é exigência de criação, isto é, na medida em que ela não é atualizada num resultado, distinguindo-se: 1 / aquilo que a vida é no seu contato com a matéria; 2 / aquilo que a vida é em si mesma.

No seu contato com a matéria, a vida é "élan", "impulsão" e designa uma orientação em sentido inverso da matéria. Ela é "exigência de criação" naquilo que ela exige da matéria efetivamente mais do que pode tirar dela. Por isso, não há criação absoluta. Só há uma criação limitada, cujos resultados manifestam um ato original prévio e que é efetuado através do que interrompe seu movimento (a matéria): "O élan vital de que falamos consiste, em suma, em uma exigência de criação. Não pode realizar uma criação total, porque encontra à sua frente a matéria, isto é, o movimento inverso ao seu" (BERGSON, 2005, p. 275). Porém, ainda mais: a interrupção do seu próprio movimento resulta de uma exigência interna à vida, em razão da própria natureza do virtual, que não existe senão em sua relação com o atual ${ }^{15}$, com o que difere dele próprio.

Dizer que o élan vital é "exigência de criação" significa que no seu contato com a matéria, a vida é um élan que se opõe a uma resistência e que em si mesma traz o que tende a limitar seu próprio jorramento. Trabalhar de maneira interna por uma vocação em se fazer outra, a vida traz em si a exigência de sua própria finitude. A exigência de criação da vida é finita. A vida se manifesta, sobre nossa terra, como evolução criadora, ou seja, como uma criação que faz sempre a experiência do seu próprio limite. E porque "a vida para se afirmar precisa dessa matéria que a mata”, como diz Jankélévitch (1975, p. 176), cada espécie

$15 \quad$ Sobre esse ponto, podemos ler as análises da finitude do élan no livro Bergson ou l'imagination métaphysique de Paul-Antoine Miquel: "Logo o virtual não é infinito senão pelo fato que ele se limita. Ele traz em si seu limite. É nesse sentido que ele sobre-vive. Ele não está de forma alguma além de todo limite. Ele é infinito. Mas não é de forma alguma ilimitado ou indeterminado. Eis a primeira tese que transforma profundamente o que chamaremos de absoluto ou infinito metafísico" (2007, p. 71). 
criada, sobre um plano de inversão qualquer, aparece como uma tentativa da vida para resistir à sua própria finitude ${ }^{16}$.

\section{Considerações finais}

A destinação da vida se realiza na duração. A evolução é criadora, pois a realidade surge-nos como um jorro ininterrupto de novidades. Nesse sentido, não se pode explicar a vida pela adaptação, pois isso seria explicar a evolução apenas pelas condições exteriores às quais corresponderia a plasticidade da vida. Pelo élan vital, e pelo processo de diferenciação, Bergson apresenta uma teoria da evolução como de um ato pelo qual a vida se divide e se bifurca. Efetivamente, apreciando a trajetória do movimento evolutivo, verificamos que ela nem é retilínea nem única. No termo de cada linha de evolução, nos aparecem seres que, embora conservando certo parentesco em virtude da sua origem comum, registram diferenças, não apenas de grau, mas de natureza. Este fato fundamenta a hipótese, admitida por Bergson, de uma explosão inicial do élan vital, à maneira de um obus de canhão. A explosão, cujas causas verdadeiras e profundas foram as que a vida levava em si mesma, provocou uma série de fragmentos cada vez mais pulverizados e, só a partir deles, nós poderemos, recuando de grau em grau, ir até ao movimento original.

Do mesmo modo que, na explosão de uma granada, a fragmentação se explica pela força explosiva e pela resistência do metal, assim também a fragmentação da vida se deve a essas duas ordens de fatores: à força explosiva da própria vida e à resistência que a matéria lhe opõe. A matéria resiste à vida, mas a vida, emergindo por meio da matéria, organiza-a, tal como a limalha de ferro (a comparação é de Bergson) oferece resistência ao braço que tenta atravessá-la, mas este, metido na limalha, a configura à sua forma, experimentando tanto maior resistência quanto mais nela se imprime.

O élan vital forma a matéria e usa dela para formar os instrumentos da sua atividade livre, porque, como dissemos, no $\overline{16}$ Conferir também CAEYMAEX (2008). 
movimento invertido permanece sempre algo do movimento natural. A matéria acaba, assim, por ser o resíduo do élan vital que, por um lado, no seu movimento ascendente, origina o espírito, mas, por outro, no seu movimento descendente ou de degradação, dá origem à matéria. Este é um dos muitos modos de evolução do élan vital, que foi impedido no seu processo evolutivo, permanecendo no seu estado inicial como tantos outros. Ao contrário, há modos de evolução que se elevam a formas mais altas, continuando assim o sentido original do ímpeto criativo.

Bergson refere-se várias vezes a direções divergentes e a vias divergentes de evolução. Fala mesmo de "duas ou três grandes linhas gerais de evolução em que se esboçam formas cada vez mais complexas, cada vez mais altas. Entre essas linhas corre uma multidão de vias secundárias nas quais, pelo contrário, se multiplicam os desvios, as paragens e os recuos" (2005, p. 121). E adverte que isso não resulta da exigência de um plano de conjunto, mas decorre do exame dos fatos, chegando mesmo a afirmar: "Um dos resultados mais claros da biologia foi mostrar que a evolução se deu seguindo linhas divergentes" (2005, p. 195).

O sentido divergente da evolução está patente em várias passagens de $A$ evolução criadora, de que destacamos alguns exemplos. Assim, ao afirmar que no percurso da evolução houve muitas bifurcações, Bergson assinala que houve também muitos impasses ao lado de duas ou três grandes vias. Destas, "uma só, aquela que sobe ao longo dos vertebrados até o homem, foi suficientemente larga para deixar passar livremente o grande sopro da vida" (2005, p. 118). E, pouco depois: "O estudo do movimento evolutivo consistirá, pois, em discernir certo número de direções divergentes" (p. 118). E, reportando-se à sua própria evolução, afirma que a evolução de que fala nunca se realiza no sentido da convergência, mas no sentido da divergência.

Bergson começa então a identificar o resultado a que conduzem essas vias de evolução, ao mesmo tempo que assinala as diferenças em um fundo de semelhança original, aduzindo os animais e os vegetais como representativos dos dois grandes desenvolvimentos divergentes da vida. Eis alguns passos a 
tal propósito: o modo de alimentação constitui uma diferença entre o animal e o vegetal, que pode fundamentar uma definição dinâmica dos dois reinos, no sentido em que marca as duas direções divergentes onde vegetais e animais tomaram o seu impulso (2005, p. 142). Assinalando que as células animal e vegetal derivam de um tronco comum, sublinha que as tendências características da evolução dos dois reinos, embora divergentes, coexistem ainda hoje, tanto na planta como no animal. Analisa depois o modo como se processa o desenvolvimento nos animais, o colocando, antes de tudo, num progresso do sistema nervoso sensório-motor e esse desenvolvimento se fez em duas direções divergentes: artrópodes e vertebrados. Derivando de um tronco comum, coexistem atualmente certas tendências destas duas vias, mas com profundas diferenças, particularmente no que se refere à independência no funcionamento dos seus órgãos, muito mais acentuada nos vertebrados e tornando-se completa no homem, em virtude da libertação das mãos. Bergson sublinha ainda o que se adivinha por detrás do que se vê: duas potências imanentes à vida e confundidas a princípio, que se foram dissociando à medida que foram evoluindo e crescendo (2005, p. 151).

Finalmente, Bergson chama a atenção para o sucesso como critério de superioridade. Neste caso, o ponto culminante atinge-se também nos vertebrados e, nestes, na espécie humana, aquela que obteve maior sucesso, já que reivindica a terra inteira para seu domínio, com uma capacidade ímpar de adaptação a todos os meios. Uma espécie assim torna-se verdadeiramente superior, podendo dizer-se que o homem é, na verdade, o dono do solo (2005, p. 152).

\section{Referências bibliográficas}

BERGSON, Henri. Oeuvres (Édition du Centenaire). Paris: PUF, 1959.

BERGSON, Henri. Mélanges. Textes publiés et annotés par André Robinet. Paris: PUF, 1972.

BERGSON, Henri. Correspondances. Textes publiés et annotés par André Robinet. Paris: PUF, 2002. 
BERGSON, Henri. L'évolution créatrice. Édition critique. Paris: PUF/ Quadrige, 2007.

BERGSON, Henri. As duas fontes da moral e da religião. Trad. Natanael C. Caixeiro. Rio de Janeiro: Zahar, 1978.

BERGSON, Henri. Ensaio sobre os dados imediatos da consciência. Tradução: João da Silva Gama. Lisboa: Edições 70, 1988.

BERGSON, Henri. Evolução criadora. Trad. Bento Prado Neto. São Paulo: Martins Fontes, 2005.

BERGSON, Henri. Matéria e memória. Trad. Paulo Neves. São Paulo: Martins Fontes, 1999.

BERGSON, Henri. O pensamento e o movente. Trad. Bento Prado Neto. São Paulo: Martins Fontes, 2006.

BERGSON, Henri. A energia espiritual. Trad. Rosemary Costhek Abílio. São Paulo: Martins Fontes, 2009.

CAEYMAEX, Florence. Négativité et finitude de l'élan vital. La lecture de Bergson par Jankélévitch. In: WORMS, Frédéric et al. (org.) Annales Bergsoniennes IV. Paris: PUF, 2008, p. 634-640.

COIMBRA, Leonardo. A Filosofia de Henri Bergson. Lisboa: Imprensa Nacional, 1994.

FRANÇOIS, Arnaud (org.). L'Évolution créatrice de Bergson. Paris: Vrin, 2010.

HUSSON, Léon. L'intellectualisme de Bergson, genèse et développement de la notion bergsonienne d'intuition. Paris: PUF, 1947.

JANKÉLÉVICH, Vladimir. Henri Bergson. Paris: PUF, 1975.

LAPOUJADE, David. Puissances du temps. Versions de Bergson. Paris: Les Éditions de Minuit, 2010.

MIQUEL, Paul-Antoine. Bergson ou l'imagination métaphysique. Paris: Editions Kimé, 2007.

PHILONENKO, Alexis. Bergson ou de la philosophie comme science rigoureuse. Paris: Cerf, 1994.

PRADO Jr., Bento. Presença e campo transcendental: Consciência e Negatividade da Filosofia de Bergson. São Paulo: EDUSP, 1989.

RUSSELL, Bertrand. La méthode scientifique em philosophie. Tradução para o francês: Philippe Devaux. Paris: Payot, 2002.

WORMS, Frédéric. Bergson ou os dois sentidos da vida. Trad. Aristóteles Angheben Predebon. São Paulo: Editora Unifesp, 2010. 